\title{
Biochar and its Use in Soil: Lessons from Temperate Agriculture
}

\author{
M Oelbermann ${ }^{1 *}, \mathrm{~F}$ Berruti $^{2}$ and V Lévesque ${ }^{3}$ \\ ${ }^{1}$ School of Environment, Resources and Sustainability, University of Waterloo, Canada \\ ${ }^{2}$ Department of Chemical and Biochemical Engineering, Institute for Chemicals and Fuels from Alternative Resources (ICFAR), Western University, Canada \\ ${ }^{3}$ Kentville Research and Development Centre, Agriculture and Agri-Food Canada, Canada
}

*Corresponding author: M Oelbermann, Professor, School of Environment, Resources and Sustainability, University of Waterloo, Canada.

Received Date: June 16, 2020

Published Date: July 09, 2020

\section{Biochar Basics}

\section{What is biochar?}

Biochar is a carbon-rich product that is obtained when a sustainable source of biomass is heated without oxygen. Biochar is produced in the same way as charcoal, but its intended use differs. Biochar is manufactured with a specific set of properties (e.g. adsorption properties, ion exchange capacity, low bulk density) for its use as soil amendment and/or adsorbent, whereas charcoal has specific properties (e.g. generating heat) for its use as a fuel. Humans first used biochar in the form of charcoal (as a byproduct from cooking) mixed with broken pottery, animal bones and manure in the Brazilian Amazon. This led to the creation of the Amazonian Dark Earths or Terra Preta more than 2000 years ago by pre-Columbian cultures of this region. Whether these soils were created intentionally or if they were a by-product of human settlements remains unclear. However, Terra Preta soils are highly fertile and have demonstrated the potential for long-term carbon sequestration (Figure 1). Based on this premise, researchers have encouraged the deliberate addition of biochar to tropical soils to enhance their fertility. From this work, it was found that biochar substantially improved soil properties and crop productivity, because adding biochar to nutrient-impoverished tropical soils decreased aluminum toxicity and increased soil $\mathrm{pH}$, resulting in enhanced microbial activity and nutrient availability. However, temperate soils have lower iron and aluminum oxide content, a higher $\mathrm{pH}$, high-activity clays and greater soil organic matter content and will therefore respond differently to biochar than tropical soils. Amending intensively managed temperate soils with biochar is a more recent approach to agriculture, with research still in its infancy. However a soil amendment like biochar that can maintain or improve soil health, potentially decrease fertilizer input and minimize nutrient leaching will not only place less pressure on soil resources but also contribute to environmental sustainability [1].

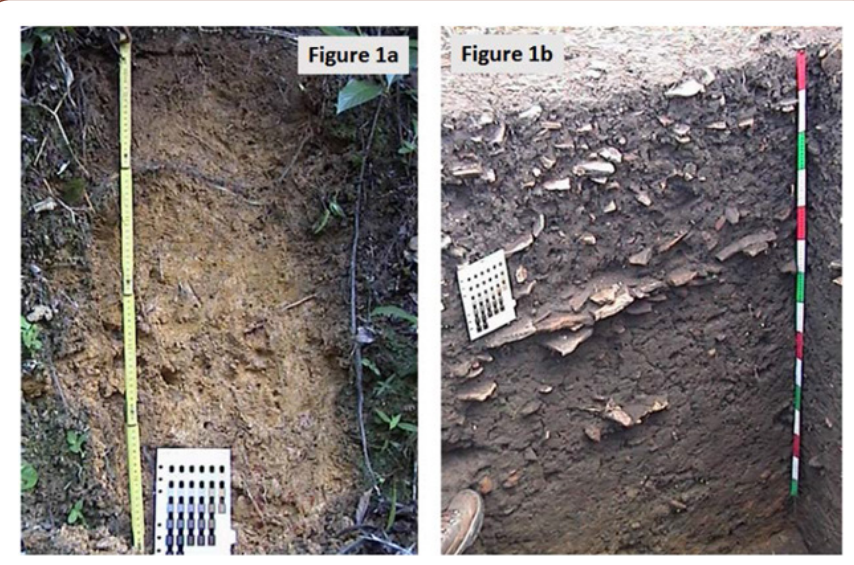

Figure 1: Highly leached tropical soil from the Amazon basin (a), and Terra Preta soil containing artefacts from Iranduba, Brazil (b). Photos used with permission and provided by J. Lehmann. 


\section{Biochar feedstocks}

Biochar can be produced from a variety of feedstocks including residues from the agricultural and forest industries (straw, rice hulls, wood chips, nut shells, wood pellets, tree bark, bagasse, manure), organic waste materials and industrial by-products (food waste, paper sludge, pulp, distillers grains), purpose grown biomass (miscanthus and switchgrass), or undesirable invasive grasses (phragmites). Due to biochar's structure, it is chemically and biologically more stable compared to the organic matter from which it is made. However, the source of the feedstock and the conditions during biochar production (pyrolysis) are major controls on the biochar's characteristics including its carbon and ash content, pH, elemental composition and stability (Table 1). Not all biochars are the same, and the benefits of biochar are not universal.
For example, biochar made from animal manure will have a higher nutrient content and is more likely to improve soil fertility. Biochar made from wood waste is more suited to carbon sequestration due to its greater long-term stability. Also, different soil textures will interact differently when the same type of biochar derived from the same feedstock is added (Table 2). Adding the same type of biochar to the same soil type but under different climates will not result in the same outcome. Recent research shows that adding biochar to coarse and medium textured soil results in greater fertility improvement than adding biochar to heavy textured soil [2]. Biochars can also be engineered to have specific physical and chemical properties by selecting desired feedstock properties and pyrolysis conditions. For example, biochars can be engineered to function as a soil amendment or as a sorbent for pollutants, such as heavy metals and pesticides [1].

Table 1: Chemical characteristics of biochars derived from various feedstocks.

\begin{tabular}{|c|c|c|c|c|c|c|c|c|c|}
\hline Feedstock & Pyrolysis & pH & $\mathrm{C}(\%)$ & N (\%) & $P(\mathrm{mg} / \mathrm{kg})$ & $\mathrm{K}(\mathrm{mg} / \mathrm{kg})$ & $\mathrm{Ca}(\mathrm{mg} / \mathrm{kg})$ & $\operatorname{Mg}(\mathrm{mg} / \mathrm{kg})$ & S (mg/kg) \\
\hline Hardwood (Maple-Oak-Birch) ${ }^{\ddagger}$ & $450{ }^{\circ} \mathrm{C}$ & 7.4 & 61.7 & 0.24 & 236 & 1714 & 23680 & 1853 & 264 \\
\hline Softwood (Pine-Spruce) ${ }^{\circ}$ & $550{ }^{\circ} \mathrm{C}$ & 7.2 & 80.0 & 0.47 & 303 & 3003 & 6795 & 2302 & 266 \\
\hline Hardwood (Maple bark)* & $400{ }^{\circ} \mathrm{C}$ & 10.1 & 59.2 & 1.02 & 962 & 7926 & 61814 & 2343 & n.d. $($ Stot $<1 \%)$ \\
\hline Hardwood (Maple bark) ${ }^{*}$ & $550^{\circ} \mathrm{C}$ & 11.3 & 54.6 & 0.93 & 1398 & 11066 & 83501 & 3320 & n.d. $($ Stot $<1 \%)$ \\
\hline Hardwood (Maple bark) $^{*}$ & $700^{\circ} \mathrm{C}$ & 11.1 & 54.0 & 0.63 & 1092 & 9018 & 67134 & 2806 & n.d. $($ Stot $<1 \%)$ \\
\hline Softwood (Pine chips) ${ }^{*}$ & $700^{\circ} \mathrm{C}$ & 7.4 & 76.1 & 1.24 & 422 & 2510 & 6426 & 1406 & n.d. $($ Stot $<1 \%)$ \\
\hline Hardwood (Willow chips) ${ }^{*}$ & $400{ }^{\circ} \mathrm{C}$ & 8.2 & 74.5 & 0.78 & 3760 & 11905 & 16865 & 2480 & n.d. $($ Stot $<1 \%)$ \\
\hline
\end{tabular}

$\ddagger$ Adapted from Dil M, et al. [4].

$\diamond$ Adapted from Mechler M, et al. [18].

*Adapted from Lévesque $V$, et al. [16].

Table 2: Soil chemical characteristics from southern Ontario with coarse (Delhi), medium (Elora) and fine (Vineland) textures amended with $1 \mathrm{t} / \mathrm{ha}$ maple-oak-birch biochar using fast pyrolysis, $450^{\circ} \mathrm{C}$.

\begin{tabular}{|c|c|c|c|c|c|c|c|}
\hline \multirow{2}{*}{ Soil Texture } & Treatment & $\mathbf{p H}$ & Carbon (\%) & $\mathrm{NH}_{4}^{+}-\mathbf{N}(\mathbf{m g} / \mathbf{k g})$ & $\mathrm{NO}_{3}^{-}-\mathbf{N}$ (mg/kg) & Corn Biomass (g/plant) & N Uptake (g N/plant) \\
\hline \multirow{2}{*}{ Coarse } & Control & 6.9 & 0.7 & 2.28 & 10.27 & 4.8 & 5.2 \\
\cline { 2 - 9 } & Biochar & 7.0 & 1.1 & 1.79 & 5.24 & 7.1 & 8.1 \\
\hline \multirow{2}{*}{ Medium } & Control & 7.4 & 2.2 & 8.12 & 7.93 & 5.3 & 8.4 \\
\cline { 2 - 9 } & Biochar & 7.2 & 2.4 & 8.77 & 4.66 & 11.0 \\
\hline Fine & Control & 7.6 & 1.6 & 10.97 & 10.41 & 17.9 & 39.2 \\
\hline
\end{tabular}

Information adapted from Dil M, et al. [5].

\section{Feedstocks and quality of biochar}

Different feedstocks have different qualities in terms of nutrient composition, and as mentioned above, if the same feedstock is processed under different pyrolysis processes, the biochar produced has different characteristics. Even using the same feedstock and pyrolysis processes can sometimes generate slight differences in biochar characteristics. This is the case for feedstocks derived from composted food waste. Therefore, using a high-quality feedstock source is important in order to avoid any negative effects on soil. Feedstock derived from contaminated sites or feedstock containing known contaminants which have been converted to biochar should not be added to agricultural soil. This is because feedstock containing heavy metals (e.g. lead, zinc, arsenic) and other contaminants will generate a low-quality biochar containing heavy metals, polycyclic aromatic hydrocarbons and dioxins, which will negatively affect the soil, plants and environment. Therefore, it is important to use biochar produced from high quality feedstock and through a consistent pyrolysis process (Figure 2). The resultant biochar should also have been characterized (e.g. carbon, nutrient and heavy metal content). According to the International Biochar Initiative, a high-quality biochar must contain at least $60 \%$ carbon. Inhibition of crop germination and earthworm avoidance can be 
used to test biochar safety. In addition, the use of a suitable biochar as soil amendment should have these two criteria of carbon (C), ox- ygen $(\mathrm{O})$ and hydrogen $(\mathrm{H})$ content according to Schimmelpfennig \& Glaser [3]: $0 / C$ ratio $<0.4$ and $\mathrm{H} / \mathrm{C}$ ratio $<0.6$.

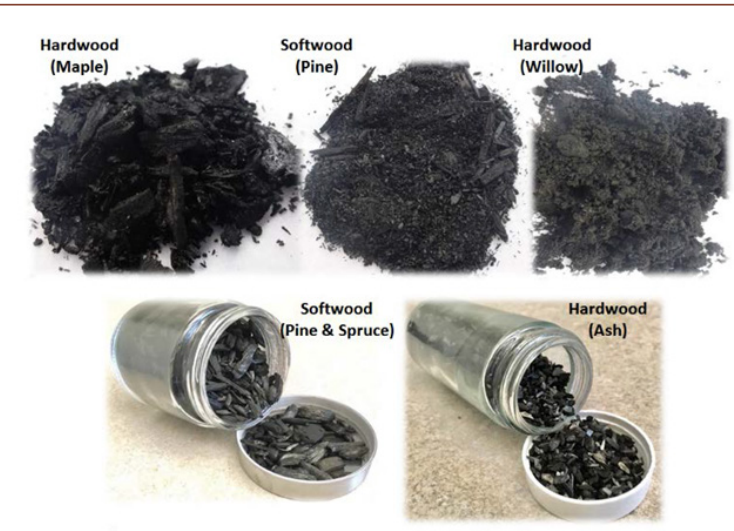

Figure 2: Different biochars generated from various feedstock types.

\section{Potential Uses of biochars}

Due to its structure and composition, there are many promising applications for biochar, such soil amendment, food or feed additive, composite materials, activated carbon, electrodes for batteries or electrolysis cells, metallurgical coke substitute, coal substitute, catalyst for tars, pharmaceutical and cosmetic, and could be eligible for carbon credits. Nanda et al. [4] have published an extensive review on the broad applications of biochar.

\section{How are biochars made?}

Several reviews have illustrated the different technologies and processes used experimentally and industrially to produce biochar [4,5]. These include torrefaction, pyrolysis, gasification, combustion and hydrothermal carbonization (Table 3). Scale and potential mobility are important considerations in relation to the feedstock supply, logistics, seasonality, further refining, products quantities, characteristics and value, and potential markets.

Table 3: Summary of experimental and industrial pathways to produce biochar.

\begin{tabular}{|c|c|}
\hline \multirow{3}{*}{ Torrefaction } & - Heating of biomass feedstock between 200 and $300^{\circ} \mathrm{C}$ \\
\hline & - Changes the properties of the biomass to generate better fuel quality for combustion or gasification \\
\hline & - $\quad$ Biochar is very hydrophobic \\
\hline \multirow[t]{2}{*}{ Pyrolysis } & $\begin{array}{l}\text { - Pyrolysis is a process that thermally decomposes biomass by heating it at elevated temperatures under controlled inert } \\
\text { conditions (low oxygen) }\end{array}$ \\
\hline & - Generates biochars with different properties depending on the pyrolysis process and results in a good biochar yield \\
\hline \multirow{2}{*}{ Gasification } & $\begin{array}{l}\text { - Heating of feedstock biomass at temperatures higher than } 750{ }^{\circ} \mathrm{C} \text { in the presence of a gasifying agent (air, oxygen or } \\
\text { steam) at atmospheric or at elevated pressures }\end{array}$ \\
\hline & - $\quad$ Results in very low yield of biochar \\
\hline \multirow{2}{*}{ Combustion } & - $\quad$ Burning of biomass feedstock at higher temperatures \\
\hline & - Yields little to no biochar \\
\hline \multirow{2}{*}{$\begin{array}{l}\text { Hydrothermal } \\
\text { Carbonization }\end{array}$} & $\begin{array}{l}\text { - Use of wet feedstock biomass under water in a sealed confined system and heated at the temperature range of } 175-300 \\
{ }^{\circ} \mathrm{C} \text { up to } 16 \text { hours under saturated pressure }\end{array}$ \\
\hline & - $\quad$ Produces a tar-free biochar, but has lower carbon stability \\
\hline
\end{tabular}

Torrefaction involves heat treatment of biomass under atmospheric pressure and within a temperature range of 200-300 ${ }^{\circ} \mathrm{C}$, without oxygen or with limited oxygen supplies. It yields char with less moisture, higher energy density, lower weight, lower $\mathrm{O} / \mathrm{C}$ and $\mathrm{H} / \mathrm{C}$ ratio, increased hydrophobic nature and resistance to biological degradation with respect to the original feedstock. Typical yields of torrefied biomass range between 50 and $80 \%$. Gasification is a thermochemical process carried out at temperatures higher than $750{ }^{\circ} \mathrm{C}$ in the presence of a gasifying agent (typically air, oxygen, or steam) at atmospheric or at elevated pressures. Under these conditions, biochar yields are not sufficiently significant to consider gasification an appropriate biochar production process. Similarly, combustion is not a suitable biochar production process, since, theoretically, under good combustion conditions, biochar yield should be negligible.

Together with torrefaction, pyrolysis and hydrothermal carbonization are the major processes used for biochar production, whose characteristics will greatly depend upon temperature, heating rate, residence time, feedstock type and physical characteristics, and reactor configuration. Hydrothermal carbonization is performed 
with wet feedstock biomass under water in a sealed confined system and heated at the temperature range of $175-300^{\circ} \mathrm{C}$ up to 16 $\mathrm{h}$ under saturated pressure under subcritical conditions producing tar-free biochar (hydrochar) with large number of functional groups. Hydrochars contain predominantly aliphatic compounds and more oxygen functional groups and higher cation exchange capacity than conventional biochars. On the other hand, they have lower surface area, micro porosity and carbon stability.

Among the various thermal technologies, pyrolysis has been the most investigated technique and considered the best technology to produce biochar. The various modes of pyrolysis include slow, intermediate, fast, flash, and ultra-pyrolysis, carried out under vacuum, atmospheric pressure or under pressure. Garcia-Nunez et al. [6] have published an extensive review on pyrolysis reactor technologies.

Due to the balance between primary, secondary cracking and recombination reactions, bio-oil yields are typically maximized (up to $70 \%)$ at intermediate temperatures $\left(450-550{ }^{\circ} \mathrm{C}\right)$, faster heating rates $\left(100-500{ }^{\circ} \mathrm{C} / \mathrm{s}\right)$ and short vapor residence times $(<1 \sim 2 \mathrm{~s})$, which are characteristic of fast and flash pyrolysis. Under these conditions, biochar yields are typically of the order of 15 20\%. On the other hand, higher biochar yields (25 40\%) are achieved at moderate temperatures $\left(300-450{ }^{\circ} \mathrm{C}\right)$, slower heating rates $(\sim 1$ ${ }^{\circ} \mathrm{C} / \mathrm{s}$ ) and longer vapor residence times (> 5 10 s), representative of slow or intermediate pyrolysis, when bio-oil yields vary between 40 and $50 \%$ with the balance being gas.

The efficiency of biochar in most applications significantly depends on its carbon and ash content, surface area, pore size distribution, alkalinity, hydrophobicity, ion-exchange capacity and elemental composition. These properties are subject to variations depending on the biochar feedstock, pyrolysis temperature, heating rate, residence time, potential oxidation medium, preand post-processing treatments. Temperature plays a prominent role in determining biochar quantity and quality. As the pyrolysis temperature increases within the broad range between $300{ }^{\circ} \mathrm{C}$ and $700{ }^{\circ} \mathrm{C}$, aromatic carbon, ash, surface area, pore volume and $\mathrm{pH}$ increase, while yield, volatile matter, hydrogen and oxygen content, conductivity and cation exchange capacity decrease. Moisture is also reported to have certain positive impacts on biochar yield. High moisture containing biomasses are found to improve the yield of biochar. Studies on woody and agricultural biomass have reported biochar yields positively correlated with lignin content. Surface area and pore volume are chief parameters to evaluate the absorption by biochar, particularly for organic molecules. Although higher processing temperatures increase the specific surface area, high heating rates favor such increases. Therefore, biochar derived at higher temperatures are more efficient for adsorption of organic contaminants due to the higher surface area and pore volume, whereas biochar generated at lower temperatures is effective for adsorption of inorganic contaminants due to greater intensity of 0 -containing functionalities and higher incidence of cationic complexes in the soil.

Based on these considerations, the quality of the biochar is strongly influenced by the reactor technology in which it is produced and on its operating conditions. Although stoves can produce biochar, its quality is highly questionable as the operating conditions are not carefully controlled. Biochars produced in batch mode are different than biochars produced in continuous operations. Mixing is a critically important parameter to ensure uniform reaction conditions and, consequently, product quality control. Mixing strongly influences heat transfer and, therefore, heating rates of the reacting biomass and, as discussed, product characteristics. Slow pyrolysis is carried out in rotating kilns, intermediate pyrolysis is auger type or mechanically mixed reactors, whereas fast pyrolysis is carried out in fluidized, circulating fluidized beds or rotating cone reactors

\section{Specific Uses of Biochar in Agriculture and Horticulture}

\section{Soil Health}

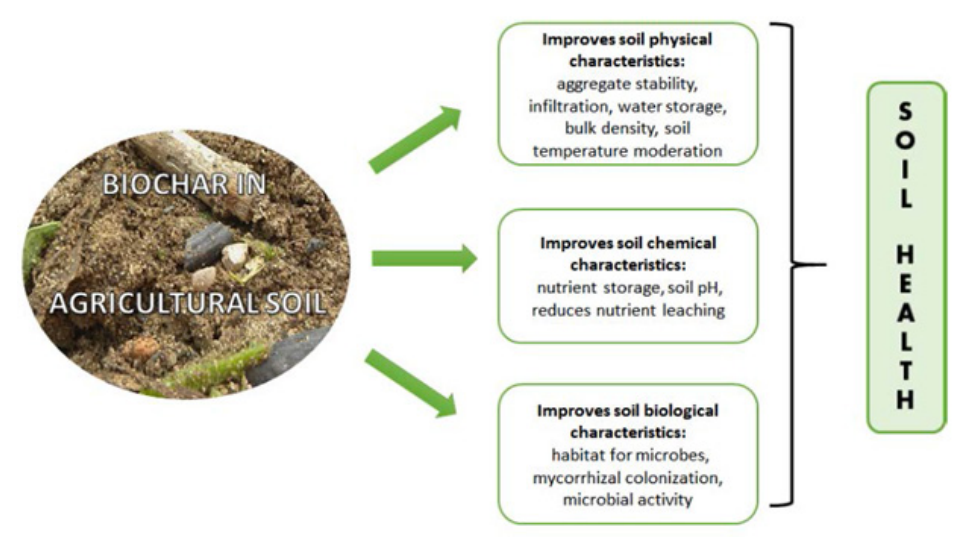

Figure 3: Influence of biochar on soil health. 
Soil health is defined as the capacity of the soil to function as a living system to sustain biological productivity, maintain environmental quality and promote plant, animal and human health [7]. The application of biochar to temperate soil has demonstrated improvement or the potential to improve a variety of soil health indicators (Figure 3). Biochar can also play an important role in higher-valued horticultural crops. In the horticultural industry, peat is a favored growing medium, but due to its long regeneration time, peat is a non-renewable resource. However, research has shown that $15 \%$ (by volume) biochar can be added to peat and improve crop productivity and soil characteristics [8]. Its labile carbon content may stimulate microbial activity and interact with roots and soil bacteria, promoting plant-growth-beneficial microorganisms in peat and in soil [2,9-11].

The following soil health characteristics, which can also be linked to the OMAFRA Soil Health Strategy (http://www.omafra gov.on.ca/english/landuse/soil-strategy.pdf), have demonstrated improvement when biochar was added to temperate soil or its use as a horticultural growing medium [1]:

- $\quad$ increase water holding capacity and infiltration by adding pore space and supporting aggregation;

- $\quad$ moderation of soil temperature extremes;

- $\quad$ soil structure through aggregation (better aggregate stability) and crop root penetration;

- $\quad$ decrease in bulk density;

- $\quad$ increase cation exchange and nutrient storage;

- $\quad$ moderation of soil acidity;

- changes in microbial community composition and substrate utilization;

- $\quad$ increase microbial activity and diversity;
- $\quad$ increase mycorrhizal fungal colonization;

- $\quad$ increase nitrogen fixation;

- $\quad$ promote beneficial microorganisms for plant growth;

- $\quad$ reduce greenhouse gas emissions.

\section{Crop productivity}

A recent survey evaluated 1000 different research studies on the effect of biochar on crop yield. Although biochar showed favorable results on crop productivity, with a $25 \%$ increase in yield in tropical environments this effect was not observed under temperate conditions. This confirmed that biochar benefits tropical soils but biochar application to the more fertile temperate soils and its effect on crop yield remains uncertain [12]. Low yield responses due to biochar addition have been observed on fertile soils and in some cases low rates of biochar addition did not result in improved crop productivity. A field study from southern Ontario (Figure 4) did not find a significant improvement in corn or soybean production when biochar, derived from pine and spruce wood waste, was added at $3 \mathrm{t} / \mathrm{ha}$ and combined with poultry manure [13]. The same study also found that the ratio of shoot to root biomass (shoot/root ratio) for corn or soybeans was lower when soil was amended with biochar. This suggested that crops produced with biochar experienced lower environmental stress (e.g. water stress) than those produced without biochar. Most researchers concur that use of a high-quality biochar in temperate soil, although it may not improve crop yield, will have no negative effects on crop productivity, but will improve soil health. The application of biochar in legume-based intercropping system with a cereal crop might be beneficial for improving cereal growth and reducing $\mathrm{N}$ fertilizer supply. According to Liu et al. [14], a maizepeanut intercrop with biochar amendment allowed a higher nodule weight on peanut roots promoting $\mathrm{N}$ fixation, favoring a higher $\mathrm{N}$ transfer from peanut to maize. There is currently no information on the effects of biochar on pasture production.
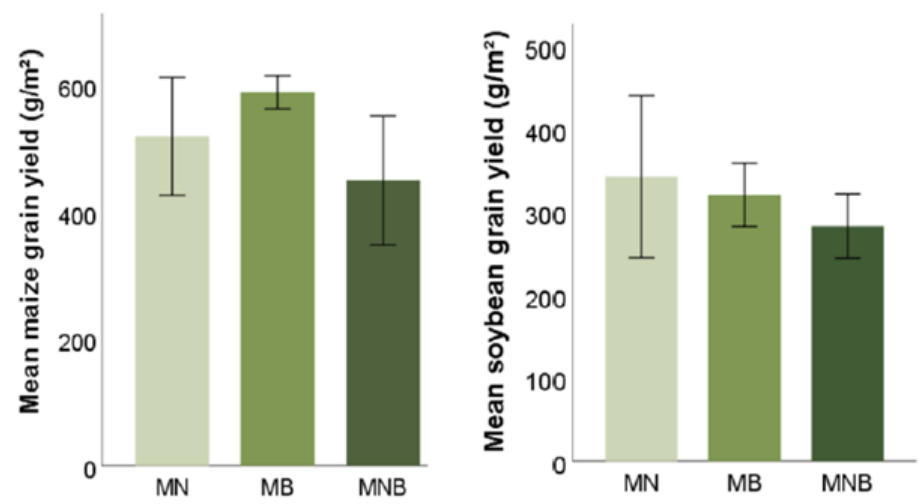

Figure 4: Soybean and maize grain yield in a loamy-textured soil amended with $6 \mathrm{t} / \mathrm{ha}$ poultry manure plus $150 \mathrm{~kg} / \mathrm{ha} \mathrm{N}$ fertilizer (MN), or 3 t/ha poultry manure plus 3 t/ha biochar (MB) or 3 t/ha poultry manure, 3 t/ha biochar, $150 \mathrm{~kg} / \mathrm{ha} \mathrm{N}$ fertilizer (MNB) in southern Ontario. Data provided by T. Silverthorn. 


\section{Nutrient leaching and crop nutrient uptake}

Biochar has the ability to retain soil nutrients such as ammonium, nitrate and phosphorus, and this effect is most readily observed in light-textured (e.g. sandy) soils. This provides an opportunity for increased nutrient uptake and reduced leaching of nutrients applied by fertilizers from entering local water sources (e.g. Ontario Great Lakes Strategy Priority: https://www.ontario. $\mathrm{ca} /$ page/ontarios-great-lakes-strategy). Some research has suggested that the ability of biochar to adsorb nutrients could result in lower fertilizer requirements; studies are currently underway to assess this component. A laboratory study found that adding a low quantity of biochar ( $1 \mathrm{t} / \mathrm{ha}$ ) combined with urea ammonium nitrate enhanced corn nitrogen uptake in a coarse-textured soil (Table 2). This study also found a higher nitrogen utilization efficiency in fine-textured soil, suggesting that biochar could serve as a carrier for nitrogen [15]. The size of the biochar particles also influences nutrient leaching potential. Typically, large ( 2 to $4 \mathrm{~mm}$ ) or medium ( 1 to $2 \mathrm{~mm}$ ) biochar particles have a better capacity to adsorb nutrients and prevent them from leaching, whereas small and very vine ( 0.05 to $1 \mathrm{~mm}$ ) biochar particles are subject to greater movement in soil and can facilitate the transport of nutrients and other agrochemicals like herbicides [16].

Some studies showed that the presence of biochar reduced phytotoxicity of herbicide residues such as atrazine. However, due to the high-binding capacity of some biochars, it could also render herbicides inactive and make them less effective in controlling weeds. Biochar with a high specific surface area, high micro porosity and highly aromatic carbon influences the persistence, release and bioavailability of herbicides [17]. Further work on this is currently underway.

\section{Greenhouse gases}

Currently, only a few field studies have evaluated temporal changes in greenhouse gas emissions in soil amended with biochar; and these studies found variable results. For carbon dioxide $\left(\mathrm{CO}_{2}\right)$ and nitrous oxide $\left(\mathrm{N}_{2} \mathrm{O}\right)$, studies conducted under field conditions reported no effect of biochar on greenhouse gas emissions [18]. A 3-year study from southern Ontario found no difference in $\mathrm{CO}_{2}$ and $\mathrm{N}_{2} \mathrm{O}$ emissions from soil amended with biochar ( $3 \mathrm{t} / \mathrm{ha}$ ), poultry manure and/or nitrogen fertilizer compared to soil without biochar [13]. However, greenhouse gas emissions, particularly $\mathrm{N}_{2} \mathrm{O}$, from biochar amended soil are also dependent upon the type of biochar used, based on feedstock type and pyrolysis processes, its addition rate, agricultural management practices, and variation in climate depending on the location of the site. There is also some evidence that the impact of biochar on $\mathrm{N}_{2} \mathrm{O}$ emissions can change over time as the biochar ages. Ageing of biochar can decrease $\mathrm{N}_{2} \mathrm{O}$ emissions with time due to stabilization of carbon and nitrogen. However, the use of biochar in mitigating greenhouse gases can also be integrated with Canada's Climate Change Mitigation Strategies (https://www. canada.ca/en/services/environment/weather/climatechange. html).

\section{Carbon sequestration and biochar stability in soil}

Soil carbon sequestration, also known as carbon farming or regenerative agriculture includes various ways of land management practices that encourage the long-term storage of carbon. Increasing carbon in soil can be achieved when the rate of addition of organic matter is greater than its rate of decomposition in soil. Biochar has a molecular structure that makes it more resistant to microbial decomposition, compared to non-pyrolyzed organic matter (e.g. crop residues, manure and cover crops), allowing it to persist in soil for 1000 to 10,0000 years. Biochar contributes to carbon stabilization by promoting aggregate stability and through its association with organo-mineral complexes. Some researchers have speculated that the presence of aged biochar reduces decomposition rates of crop-derived residue carbon in soil and increases crop residue stabilization in soil aggregates [19]. In southern Ontario, a 3-year study did not find an increase in soil organic carbon when biochar was added to soil [13]. This is because measurable changes in soil organic carbon are difficult to detect over the short-term ( $<10$ years), and variation among years have been observed since the soil is not in equilibrium. However, the field study from southern Ontario found a greater concentration of extractable carbon in soil amended with biochar, indicating that a readily available carbon source for the microbial community was present. This suggests that a greater accumulation of decomposing organic matter was likely derived from the biochar and/or its interaction with soil organic carbon and crop roots.

The stability of biochar applied to soil depends on the biochars properties and soil mineralogical composition. Evaluating the impact of biochar on soil carbon sequestration and stabilization is difficult since most of these changes are not readily observed over the short-term. Simulation models, if calibrated to the study site's environmental conditions (e.g. climate and soil characteristics) and land management practices can provide insight into the potential long-term effect of biochar on soil carbon. For example, Dil \& Oelbermann [20] simulated the effect of biochar addition on soil organic carbon stocks over 150 years based on soil collected in southern Ontario from Elora (medium texture), Delhi (coarse texture) and Vineland (fine texture). Using the Century soil organic matter model, they found that a once application of maple-oakbirch derived biochar at $2 \mathrm{t} / \mathrm{ha}$, compared to other management practices including maize-soybean rotation, continuous maize, addition of manure, and no till, led to a greater increase and longterm stabilization of soil organic carbon at the Elora and Delhi sites. They also found that the quantity of carbon stabilized was influenced by the soil texture, and soil texture also influenced whether carbon was stabilized in active, slow or passive carbon fractions.

\section{Other uses of biochar in agriculture}

Recently, the use of biochar as a livestock feed supplement has also received some interest from the agricultural community. The benefits of biochar as a feed supplement may influence animal 
health for gastrointestinal decontamination and nutrition. Some studies have shown an improvement in production and livestock health. There has also been some research into using biochar to help reduce ruminant methane production. In southern Ontario, University of Guelph's Dr. A. Carpenter (Ridgetown campus) is investigating various aspects of biochar as a feed supplement in dairy cows.

\section{Some Precautions}

\section{Biochar storage and handling}

Biochar can form explosive mixtures with air in confined spaces. There is also a danger of spontaneous heating and ignition when biochar is tightly packed. Fresh biochar quickly adsorbs oxygen and moisture, which can lead to high temperatures and ignition. Volatile compounds in biochar can also present a fire hazard, which is more of a concern for low quality biochar. When biochar is mixed with other amendments such as manure or composts, its potential to become flammable is greatly reduced.

\section{Incorporation of biochar with soil}

Depending on the feedstock and the process used to generate biochar, the resultant product can take on many forms ranging from coarse to powdered material. Researchers suggest that it is important to retain a coarser structure of the biochar as this maintains its ability to hold water, nutrients and encourages microbial activity. If biochar is incorporated into the soil as a powder (less than 50 microns in size), then its capacity to hold water and nutrients are lost. However, biochars can also be generated for a specific purpose e.g. enhanced nutrient adsorption.

Uniform topsoil mixing can be achieved by mechanically applying biochar using a spreader and then mixing it into the soil by ploughing or disking. When mixing biochar with other amendments, the same approach of uniform topsoil mixing can be used. In certain management systems e.g. orchards or vineyards, the biochar is mixed with the other amendment(s) and top dressed between rows of trees or vines. Incorporation of biochar with liquid manures can be done when the biochar is applied to the soil surface in a uniform layer or incorporated into the soil. This can, however, cause blockages of flow in the liquid manure applicator if biochar particles are large or a high quantity of biochar is used. Therefore, testing of viscosity and flow of the biochar-liquid manure mixture is recommended prior to its application at the field scale. Deep banding of biochar allows for the placement of the biochar directly into the rhizosphere of the crop and reduces risk of biochar loss via erosion. Top dressing biochar is a desirable approach in no-till systems. However, with top dressing there is a risk of water and wind erosion, especially if biochar particles have a fine texture. This can be avoided if biochar is mixed with moist manure.

\section{Application rates and combination with other amendments}

The optimal rate of biochar application to agricultural soil has not yet been established. Average application rates ranged from as low as $3 \mathrm{t} / \mathrm{ha}$ to $50 \mathrm{t} / \mathrm{ha}$. Optimal rates will depend on biochar type, soil characteristics and management objectives. To date, the majority of studies that evaluated the impact of biochar on temperate soil have added large quantities of biochar (10 t/ha), but this may also not be a cost-effective approach to produce field crops. However, the horticultural industry that produces high-value vegetable crops, the use of biochar as a growing medium may be a more cost-effective approach compared to currently used growing media [8].

For field crops, researchers are in agreement that adding only biochar to temperate agricultural soil will likely result in a minimal, if any, improvement especially in fine-textured (clay) soil. Instead, biochar is more effective when mixed with other soil amendments such as solid or liquid manure, compost and/or fertilizers [21]. This will improve the efficiency of the biochar and the other amendment(s) than when applied alone. Adding biochar also reduces the odor of some manures. Biochar can be applied as a single application which can provide benefits for several years due to its recalcitrance. Since biochar ages in soil and its interaction with soil changes with time, it is not necessary to apply biochar at each crop seeding. However, field data is currently not available if it is more effective to apply a large dose of biochar at once, or if yearly applications at lower rates is more desirable.

\section{Next Steps: How to Integrate Biochar on Your Farm}

\section{Which biochar to use?}

The performance and stability of biochar in soil are highly dependent on soil types, plant species, and climate. Growers interested in using biochar on their property should apply it to a small area of their farm and then monitor results in subsequent years [22]. Several key points should be kept in mind when considering the use of biochar as a soil amendment:

- $\quad$ soil texture and fertility;

- $\quad$ nutritional requirements of the plant;

- $\quad$ local climate;

- $\quad$ feedstock quality and pyrolysis process;

- $\quad$ biochar particle size;

- $\quad$ which other amendments will the biochar be mixed with mineral fertilizer, manure, or other types of organic amendments such as compost;

- what is the objective of using biochar: nutrient retention, improved soil health, carbon sequestration and/or greenhouse gas reduction, etc. For example, biochar used for carbon sequestration should be derived from wood feedstock (high-carbon source) produced at high pyrolysis temperatures for long-term stability. Using biochar with the intended use of increasing soil health/ fertility should be derived from a feedstock with a greater nutrient content such as manure. It is recommended that available nutrients, rather than total nutrients, in the biochar should be measured [23] 


\section{Where to obtain biochar?}

There is an increasing interest in integrating biochar and biochar-products in agriculture. However, logistical difficulties in obtaining biochar and the current high costs of biochar, since it is still mostly an experimental product [1], have led to some smallscale on-site pyrolysis projects. Although do-it-yourself biochar production may be more cost effective, there are some potential problems with this approach:

- lack of controlled pyrolysis conditions that result in biochar with variable characteristics and therefore an inconsistent product;

- inability to capture toxic and/or greenhouse gases produced during pyrolysis;

- contamination of feedstock with heavy metals;

- lack of biochar characterization.

Although biochar obtained from external sources is more expensive, there are several advantages when using biochar derived from an established and reputable producer:

- $\quad$ availability of biochar from different and high-quality feedstocks;

- $\quad$ consistent and high-quality biochar;

- $\quad$ characterization of biochars attributes;

- $\quad$ capture of gases produced during pyrolysis.

As the biochar market continues to advance, including the development of cost-effective mobile units that reduce transportation costs, applications at the farm-scale will become more economical in time.

\section{Acknowledgement}

This work was generously supported by the Ontario Ministry of Agriculture, Food and Rural Affairs (OMAFRA). We also thank the University of Waterloo and the Canadian Foundation for Innovation for providing infrastructure support. Graduate students were supported by OMAFRA, Ontario Graduate Scholarship (OGS) and the Natural Sciences and Engineering Research Council (NSERC). We thank H\&N Baker Farms for supporting our field work and providing the field site that contributed to the completion of this document.

\section{Conflict of Interest}

No conflict of interest.

\section{References}

1. Belcher RW, Jarand ML (2017) Biochars for use in composting, US Patent

2. Brassard P, Godbout S, Lévesque V, Palacios JH, Raghavan V, et al. (2019) Biochar for soil amendment. In Jeguirim M, Limousy L (Eds). Char and Carbon Materials Derived from Biomass. Production, characterization and applications. Elsevier, Netherlands, pp. 109-148.
3. Cheng N, Peng Y, Kong Y, Li J, Sun C (2018) Combined effects of biochar addition and nitrogen fertilizer reduction on the rhizosphere metabolomics of maize (Zea mays L.) seedlings. Plant and Soil 433: 1935.

4. Dil M, Oelbermann M (2014) Evaluating the long-term effects of nitrogenenriched biochar on soil organic carbon and nitrogen using the Century model. In: Oelbermann, M. Sustainable Agroecosystems in Climate Change Mitigation. Wageningen Academic Publishers, Netherlands, pp. 249-268.

5. Dil M, Oelbermann M, Xue W (2014) The influence of nitrogenenriched biochar on maize (Zea mays L.) biomass and soil biochemical characteristics. Canadian Journal of Soil Science 94: 551-562.

6. Doran JW, Zeiss MR (2000) Soil health and sustainability: managing the biotic component of soil quality. Applied Soil Ecology 15(1): 3-11.

7. Fidel RB, Laird DA, Parkin TB (2019) Effect of biochar on soil greenhouse gas emissions at the laboratory and field scales. Soil Systems 3(8): 1-12.

8. Garcia-Nunez JA, Pelaez-Samaniego MR, Garcia-Perez ME, Fonts I, Abrego J, et al. (2017) Historical Developments of Pyrolysis Reactors: A Review 31(6): 5751-5775.

9. Glaser B, Haumaier L, Guggenberger G, Zech W (2001) The "Terra Preta" phenomenon: A model for sustainable agriculture in the humid tropics. Naturwissenschaften 88: 37-41.

10. Hernandez-Soriano MC, Kerr B, Goos P, Hardy B, Dufey J, et al. (2016) Long-term effect of biochar on the stabilization of recent carbon: soils with historical inputs of charcoal. Global Change Biology Bioenergy 8: 371-381.

11. Jaiswal A, Elad Y, Paudel I, Graber ER, Cytryn E, et al. (2017) Linking the belowground microbial composition, diversity and activity to soilborne disease suppression and growth promotion of tomato amended with biochar. Scientific Reports 7: 44382.

12. Jeffrey S, Abalos D, Prodana M, Bastos AC, van Groeninen JW, et al. (2017) Biochar boosts tropical but not temperate crop yields. Environmental Research Letters 12: 1-7.

13. Kolton M, Harel YM, Pasternak Z, Graber ER, Elad Y, et al. (2011) Impact of biochar application to soil on the root-associated bacterial community structure of fully developed greenhouse pepper plants. Applied and Environmental Microbiology 77: 4924-4930.

14. Kolton M, Graber ER, Tsehansky L, Elad Y, Cytryn E (2017) Biocharstimulated plant performance is strongly linked to microbial diversity and metabolic potential in the rhizosphere. New Phytologist 213: 13931404.

15. Lehmann J, Joseph S (2015) Biochar for environmental management: science and technology. 2nd edition. Routledge.

16. Lévesque V, Rochette P, Ziadi N, Dorais M, Antoun H (2018) Mitigation of $\mathrm{CO}_{2}, \mathrm{CH}_{4}$ and $\mathrm{N}_{2} \mathrm{O}$ from a fertigated horticultural growing medium amended with biochars and a compost. Applied Soil Ecology 126: 129139.

17. Liu L, Wang Y, Yan X, Li J, Jiao N, et al. (2017) Biochar amendments increase the yield advantage of legume-based intercropping systems over monoculture. Agriculture, Ecosystems and Environment 237: 1623.

18. Mechler M, Jiang R, Silverthorn TK, Oelbermann M (2018) Impact of biochar on soil characteristics and greenhouse gas emissions: a field study. Biomass \& Bioenergy 118: 154-162.

19. Mendes-Ferreira K, Junior-Dias AF, Takeshita V, Rego APJ, Tornisielo VL (2018) Effect of biochar amendments on the sorption and desorption of herbicides in agricultural soil.

20. Meyer S, Glaser B, Quicker P (2011) Technical, economical, and climaterelated aspects of biochar production technologies: a literature review. Environ Sci Technol 45: 9473-9483. 
21. Nanda S, Dalai AK, Berruti F, Kozinski JA (2015) Biochar as an exceptional bioresource for energy, agronomy, carbon sequestration, activated carbon and specialty materials, Waste Biomass Valorization 7: 201-235.

22. Schimmelpfennig S, Glaser B (2012) One step forward toward characterization: Some important material properties to distinguish biochars. (Special Issue: environmental benefits of biochar.). Journal of Environmental Quality 41: 1001-1013.
23. Verheijen FGA, Zhuravel A, Silva C, Amaro A, Ben-Hur M, et al. (2019) The influence of biochar particle size and concentration on bulk density and maximum water holding capacity of sandy versus sandy loam soil in a column experiment. Geoderma 347: 194-202. 